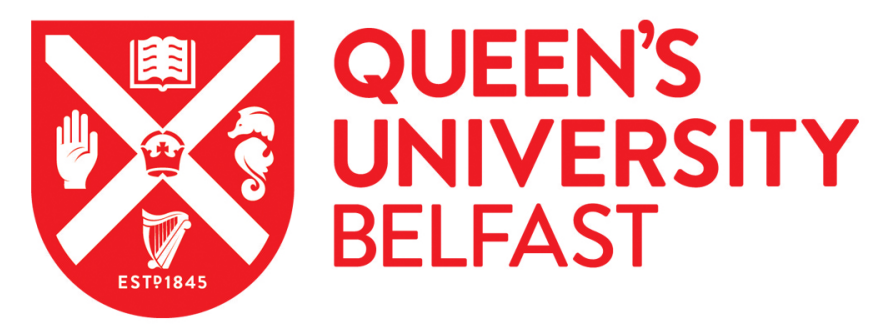

\title{
Using prednisolone and cortisol assays to assess adherence in oral corticosteroid dependant asthma: an analysis of test-retest repeatability
}

Busby, J., Holweg, C. T., Chai, A., Bradding, P., Chaudhuri, R., Mansur, A. H., Matthews, J. G., Menzies-Gow, A., Lordan, J., \& Heaney, L. (2020). Using prednisolone and cortisol assays to assess adherence in oral corticosteroid dependant asthma: an analysis of test-retest repeatability. Pulmonary Pharmacology and Therapeutics, 64, [101951]. https://doi.org/10.1016/j.pupt.2020.101951

Published in:

Pulmonary Pharmacology and Therapeutics

Document Version:

Peer reviewed version

Queen's University Belfast - Research Portal:

Link to publication record in Queen's University Belfast Research Portal

\section{Publisher rights}

Copyright 2020 Elsevier.

This manuscript is distributed under a Creative Commons Attribution-NonCommercial-NoDerivs License

(https://creativecommons.org/licenses/by-nc-nd/4.0/), which permits distribution and reproduction for non-commercial purposes, provided the author and source are cited

\section{General rights}

Copyright for the publications made accessible via the Queen's University Belfast Research Portal is retained by the author(s) and / or other copyright owners and it is a condition of accessing these publications that users recognise and abide by the legal requirements associated with these rights.

Take down policy

The Research Portal is Queen's institutional repository that provides access to Queen's research output. Every effort has been made to ensure that content in the Research Portal does not infringe any person's rights, or applicable UK laws. If you discover content in the

Research Portal that you believe breaches copyright or violates any law, please contact openaccess@qub.ac.uk. 
Title: Using prednisolone and cortisol assays to assess adherence in oral corticosteroid dependant asthma: an analysis of test-retest repeatability

Authors: John Busby ${ }^{1}$, Cecile Holweg ${ }^{2}$, Akiko Chai ${ }^{2}$, Peter Bradding ${ }^{3}$, Rekha Chaudhuri ${ }^{4}$, Adel Mansur ${ }^{5}$, John G Matthews ${ }^{2}$, Andrew Menzies-Gow ${ }^{6}$, James Lordan ${ }^{7}$, Rob Niven $^{8}$, Liam G Heaney ${ }^{1}$ in collaboration with the UK Refractory Asthma Stratification Programme (RASPUK).

${ }^{1}$ Queen's University Belfast, ${ }^{2}$ Genentech Inc., ${ }^{3}$ University of Leicester, ${ }^{4}$ Gartnavel General Hospital and University of Glasgow, ${ }^{5}$ University of Birmingham, ${ }^{6}$ Royal Brompton \& Harefield NHS Foundation Trust, ${ }^{7}$ Freemans Hospital Newcastle upon Tyne Hospitals NHS Foundation Trust, ${ }^{8}$ The University of Manchester

Correspondence: John Busby, Centre for Public Health, Institute of Clinical Sciences, Belfast, BT12 6BA, john.busby@qub.ac.uk

\section{Summary at a Glance:}

- This is the first study to assess the test-retest reliability of a simple rule combining prednisolone and cortisol measurements.

- We found this rule has almost perfect reliability and is correlated with change in blood eosinophils.

- Our results suggest clinicians should have confidence in this test to assess oral corticosteroid adherence. 


\begin{abstract}
Background and objective: Non-adherence is an important issue within severe asthma. Prednisolone and cortisol assays have been proposed as an inexpensive, objective measure of adherence for oral corticosteroid (OCS)-dependent asthmatics, however, little is known about the reliability of these tests.
\end{abstract}

Methods: 41 severe OCS-dependent asthmatics had their prednisolone and cortisol measured during six study visits over a three month time period. Subjects were classed as non-adherent/variably-adherent if they had undetectable prednisolone and/or cortisol >100 $\mathrm{nmol} / \mathrm{L}$. Intraclass correlation coefficients (ICCs) were used to assess the test-retest reliability of prednisolone and cortisol, and Gwets $\mathrm{AC}_{1}$ kappa was used to assess the reliability of the adherence classification. Mean change in blood eosinophils for adherent and variably/nonadherent visits were calculated and linear regression with cluster-robust standard errors was used to test for differences.

Results: 30 subjects were included in the analysis. Reliability was poor for prednisolone (ICC: $0.43 ; 95 \% \mathrm{Cl}: 0.27,0.59$ ), and moderate for cortisol (ICC: $0.60 ; 95 \% \mathrm{Cl}: 0.44,0.74)$. Using the combined rule, subjects were classified as adherent during 141 (88\%) visits, with 21 subjects (70\%) adherent during all study visits. The adherence classification had almost perfect reliability (Kappa: 0.84; 95\% Cl: 0.74, 0.95). Blood eosinophils were decreased by $47 \mathrm{cells} / \mu \mathrm{l}$ (95\% Cl: 11, 84) during adherent visits but increased by 65 cells/ $\mu \mathrm{l}(95 \% \mathrm{Cl}:-4,134$; $P_{\text {difference }}=0.03$ ) during variably/non-adherent visits.

Conclusions: Assessing adherence to maintenance OCS using a simple rule based on prednisolone and cortisol assays is highly reliable and correlated with blood eosinophil changes. Clinicians should have confidence in the results of this rule.

Keywords: asthma, adherence, prednisolone, cortisol

Abbreviations: ICC: intra-class correlation coefficients; LLD: lower limit of detection 


\section{Background}

Non-adherence to maintenance medications is an important contributor to poor asthma control and has recently been highlighted as a key research priority. ${ }^{1}$ Approximately $25-45 \%$ of patients referred to specialist difficult-to-control asthma services are thought to be nonadherent to their oral corticosteroid (OCS) treatment ${ }^{2-4}$, and the substantial placebo effect of up to $42 \%$ found within OCS sparing studies suggests poor background adherence. ${ }^{5,6}$ OCS have been shown to reduce asthma symptoms, improve lung function, and lower markers of type-2 inflammation. ${ }^{7,} 8$ Therefore, improved detection of sub-optimal adherence to maintenance OCS could enable better phenotyping of individual patients and enhanced targeting of adherence-improving interventions.

Various methods have been used to assess medication adherence including electronic monitoring, drug assays and pharmacy fill records. ${ }^{2}$ In OCS-dependent asthmatics, a small group who drive much of the healthcare cost of asthma 9,10 , blood prednisolone levels and suppressed cortisol have been suggested as an inexpensive, objective measure of adherence. ${ }^{3}$ This measure has been widely adopted, however, little is known about the reliability of these tests. Verification of maintenance medication adherence is used as a criterion to guide progression to high-cost biologic therapies in some countries ${ }^{11}$, making it important to understand the longitudinal stability of these measurements.

The aim of this study is to examine the stability of prednisolone and cortisol adherence measures in subjects with severe OCS-dependent asthma. 


\section{Methods}

\section{Subjects}

Participants aged between 12 and 75 years, with well characterised severe asthma receiving a minimum maintenance dose of $10 \mathrm{mg}$ prednisolone per day for at least 6 months were recruited from severe asthma centres contributing to the UK Severe Registry between July 2013 and February 2014. ${ }^{9}$ Participants were excluded if they had a FEV 1 less than $40 \%$ predicted, had an asthma exacerbation or major episode of infection less than 28 days before screening, were a current or ex-smoker ( $>15$ pack-years), or had a body mass index (BMI) >38 $\mathrm{kg} / \mathrm{m} 2$. Full details of study inclusion criteria are given in Appendix 1. Ethnical approval was granted by the National Research Ethics Service East of England (Cambridge South Committee Ref: 13/EE/0099). The clinical trial was registered on ClincalTrials.Gov (https://clinicaltrials.gov/ct2/show/NCT01948401).

\section{Study Overview and Measurements}

This study was nested within an interventional open-label clinical study investigating the impact of high-dose OCS on markers of type-2 inflammation. Full details are given elsewhere ${ }^{12}$. Briefly subjects who were thought to be adherent with maintenance medications at screening based on prednisolone/cortisol levels (visit 1) were offered a sevenday escalation of OCS $(0.5 \mathrm{mg} / \mathrm{kg}$ to the nearest $5 \mathrm{mg})$ at visit 2 (14 days after visit 1$)$ and invited to attend four follow-up visits 22 (visit 3), 53 (visit 4), 71 (visit 5) and 109 (visit 6) days after visit 1.

Serum prednisolone (lower limit of detection $[$ LLD] = $1.39 \mathrm{nmol} / \mathrm{L})$, serum cortisol $($ LLD = 2.8 $\mathrm{nmol} / \mathrm{L}$ ) and blood eosinophil counts were measured at a central laboratory. Subjects were excluded if both prednisolone and cortisol measurements were not available during at least two study visits. Cortisol measurements under $100 \mathrm{nmol} / \mathrm{L}$ were defined as abnormal and consistent with regular prednisolone use. ${ }^{13,14}$ The impact of a $50 \mathrm{nmol} / \mathrm{L}$ and $150 \mathrm{nmol} / \mathrm{L}$ threshold for normal cortisol was assessed in sensitivity analysis. Detectable serum prednisolone levels would be expected in patients taking regular prednisolone. We dichotomised prednisolone/cortisol levels and applied previously-used criteria ${ }^{2,3}$ to assess treatment adherence: 
1. Adherent: detectable prednisolone and suppressed cortisol

2. Variable adherence: detectable prednisolone and normal cortisol, or undetectable prednisolone and suppressed cortisol

3. Non-adherent: undetectable prednisolone and normal cortisol

\section{Statistical Analysis}

Subject demographics are presented using the mean (SD), median (IQR) or counts (\%) as appropriate. Trends in prednisolone, cortisol and adherence category were displayed graphically. These included an indication of whether the measurement was taken in the morning (before $12.00 \mathrm{pm}$ ) or afternoon (after $12.00 \mathrm{pm}$ ) as prednisolone is rapidly absorbed, and cortisol displays diurnal variation. ${ }^{15,16}$ We conducted a complete case analysis meaning that visits with incomplete data were excluded.

Random-effect linear models were fitted to calculate intra-class correlation coefficients (ICCS) for the absolute values of prednisolone and cortisol (dependent variables) with parametric bootstrapped confidence intervals. ${ }^{17}$ The ICC estimates the proportion of the total variation which is due to between-subject differences. ${ }^{18}$ Therefore, if patients have consistent measurements at each study visit (i.e. low within-subject variation) the ICC would be close to one. Values less than 0.50 , between 0.51 and 0.75 , between 0.76 and 0.9 , and greater than 0.91 are indicative of poor, moderate, good, and excellent reliability, respectively. ${ }^{19}$ Gwets $A C_{1}$ kappa was used to calculate the test-retest reliability for the derived adherence category variable. ${ }^{20}$ The Kappa statistic estimates the percentage agreement in the adherence category across study visits after accounting for random chance agreement. ${ }^{21}$ If patients are consistently classified to the same adherence category at each study visit the kappa statistic would be close to one. Gwets $\mathrm{AC}_{1}$ kappa is more stable than other measures of reliability (e.g. Fleiss' kappa), and is less affected by prevalence and unbalanced marginal probabilities. ${ }^{22}$ Values less than 0.20 , between 0.21 and 0.40 , between 0.41 and 0.60 , between 0.61 and 0.80 , and greater than 0.81 are indicative of slight, fair, moderate, substantial and almost perfect reliability, respectively. ${ }^{22,23}$

It is known that high-dose prednisolone temporarily suppresses blood eosinophil counts. ${ }^{24,25}$ Therefore, to assess the validity of the adherence classifications (based on prednisolone and 
cortisol assays), the mean change in blood eosinophils from study entry was calculated for visits where the subject was classified as adherent, and variably/non-adherent. Linear regression, with cluster robust standard errors to account for non-independence, was used to test for differences between these groups. ${ }^{26}$ Furthermore, a decrease in blood eosinophils between visit 2 and 3, suggesting adherence with the corticosteroid boost, was used to verify that the subjects were able to comply with OCS treatment. 


\section{Results}

\section{Subject characteristics}

Demographic and clinical details of the study cohort are given in Table 1. In total, 41 subjects were recruited and 30 provided complete prednisolone and cortisol data during at least two study visits. Of note, study participants were generally middle-aged (mean age: 53.2 [SD: 9.1] years), overweight (mean BMI: 31.0 [SD: 4.3$] \mathrm{kg} / \mathrm{m}^{2}$ ) and had poor asthma control (mean ACQ-7 score: 3.1 [SD: 1.1]). The median prednisolone and cortisol level at visit 1 were 454 nmol/L (IQR: 21,678$)$ and $18 \mathrm{nmol} / \mathrm{L}($ IQR: 11,44$)$ respectively.

\section{Prednisolone and cortisol measurements}

Twenty-seven (90\%) subjects provided prednisolone measurements at all six visits, while 3 (10\%) subjects provided measurements at five visits yielding 177 measurements in total (Figure 1, Appendix 2). The majority of prednisolone measurements were taken in the morning ( $n=148 ; 84 \%)$ and 170 (96\%) demonstrated detectable levels. The ICC for prednisolone was $0.43(95 \% \mathrm{Cl}: 0.27,0.59)$ suggesting poor test-retest reliability. Some subjects exhibited extreme variability between visits (Figure 1, Appendix 2), for example, subject 6 had prednisolone levels of 44,1238, 127 and $1351 \mathrm{Nmol} / \mathrm{L}$ during visits 3, 4, 5 and 6 respectively. Conversely, other subjects had extremely consistent levels, for example subject 26 had prednisolone measurements between 6 and $11 \mathrm{Nmol} / \mathrm{L}$, and subject 18 had levels between 3 and $49 \mathrm{Nmol} / \mathrm{L}$, during each of the six study visits.

Twenty (67\%) subjects provided cortisol at all six visits, $6(20 \%)$ at five visits, and $4(13 \%)$ at four or fewer visits yielding a total of 163 measurements (Figure 2, Appendix 2). Again, the majority were morning samples ( $n=135,83 \%) .145$ (89.0\%) were suppressed (<100nmol/L), and $22(73 \%)$ subjects had suppressed cortisol levels during all visits. The ICC for cortisol was $0.60(95 \% \mathrm{Cl}: 0.44,0.74)$ suggesting moderate test reliability. Although cortisol measurements were relatively stable for most subjects, there was notable variability in some cases. For example, cortisol increased from 110 to $406 \mathrm{nmol} / \mathrm{L}$ between visit 1 and 2 for subject 6 , and from 11 to $212 \mathrm{nmol} / \mathrm{L}$ between visit 1 and 2 for subject 27 .

\section{Assessing medication adherence}


Subjects provided both cortisol and prednisolone measurements at 161 (89\%) visits, including $18(60 \%)$ subjects who provided measurements at all six visits. Subjects were classified as adherent during $141(88 \%)$ visits, and the majority of subjects ( $n=21 ; 70 \%)$ were classified as adherent throughout the study (Figure 3). Gwets $\mathrm{AC}_{1}$ kappa was 0.84 (95\% $\mathrm{Cl}: 0.74,0.95$ ) indicating almost perfect reliability. One subject (subject 27) was classified as non-adherent during four visits. Despite high prednisolone (909 nmol/L) and suppressed cortisol (11 nmol/L) at visit 1 , they had undetectable prednisolone at four subsequent visits and cortisol levels up to $312 \mathrm{nmol} / \mathrm{L}$, suggesting a shift to medication non-adherence. Our measure of reliability was unchanged when increasing the normal cortisol threshold to $150 \mathrm{Nmol} / \mathrm{L}$ (Gwets $\mathrm{AC}_{1}$ kappa: $0.89 ; 95 \% \mathrm{Cl}: 0.80,0.99$ ), but, was slightly lower when reducing it to $50 \mathrm{nmol} / \mathrm{L}$ (Gwets $\mathrm{AC}_{1}$ kappa: 0.70; 95\% Cl: 0.54, 0.85).

\section{Blood eosinophil response and association with adherence categories}

Change in blood eosinophil count aligned well with adherence categories. Subjects defined as adherent had a mean decrease in their blood eosinophils of 47 cells/ $\mu \mathrm{l}(95 \% \mathrm{Cl}: 11,84)$ from visit 1. Those categorised as variably- or non-adherent had a mean increase of 65 cells $/ \mu \mathrm{l}(95 \%$ $\mathrm{Cl}:-4.4,134 ; \mathrm{P}=0.03)$.

Blood eosinophil count decreased (median=115 cells/ $\mu$, range: $20-520$ ) after the steroid boost in $20(71.4 \%)$ of the 28 subjects providing measurements at both visit 2 and 3, suggesting good adherence to the steroid boost. Eosinophil counts were low before the steroid boost in 7 of the remaining subjects (median=80 cells $/ \mu \mathrm{l}$, range: $0-150$ ) perhaps suggesting maximal suppression on study entry. Subject 17's blood eosinophils increased from 330 to 430 cells/ $\mu$ l after the steroid boost. 


\section{Discussion}

In a cohort of subjects thought to be adherent with maintenance OCS at study screening, we found that assessments of adherence based on combined prednisolone and cortisol assays during six study visits spanning a three month time period were almost perfectly reliable and associated with blood eosinophil change. Absolute levels of prednisolone and cortisol were poor and moderately reliable respectively.

Our results should provide clinicians with guidance on interpreting serum prednisolone and cortisol levels in clinical practice. They demonstrate that absolute prednisolone and cortisol levels are only moderately reliable, with some subjects exhibiting extreme variability between visits, confirming their limited utility. This is unsurprising as prednisolone values are known to vary with time of ingestion, whether taken with food, and whether enteric-coated preparations are used suggesting that patient behaviour on the day of clinic visit could substantially affect the test results. ${ }^{27,28}$ Clinicians should combine prednisolone and cortisol measurements using the simple rule employed in this study to evaluate adherence to oral prednisolone. Our findings do not support that patients recruited to clinical trials are substantially non-adherent with OCS, however, they do suggest some may be over-treated with systemic steroids. For example, 7 of 28 subjects had maximally suppressed blood eosinophil counts upon study entry suggesting they might have had a baseline reduction in OCS with no loss of asthma control. This may explain why placebo responses can be high in OCS sparing studies when OCS optimisation is titrated against measures of asthma control. ${ }^{5,}$ 6

Increased uptake of objective measures to assess OCS adherence could improve patient outcomes, as these medications are associated with reduced asthma symptoms and improved lung function. ${ }^{7,8}$ Studies of interventions to improve OCS compliance are sparse, however accurate identification of non-compliant patients is a crucial first-step to developing effective interventions. Our results are relevant to clinical practice, where verification of maintenance medication adherence is used as a criteria to guide biologic treatment in some countries $^{11}$, and to investigators conducting OCS-sparing studies, where confirmation of baseline adherence is necessary to estimate the true treatment effect. 
To our knowledge, this is the first study to assess the longitudinal stability of prednisolone and cortisol assays. It was nested within a robustly monitored observational clinical study with measurement of prednisolone and cortisol levels by a central laboratory. Patients were enrolled into the study based on objective measures of adherence, and findings of decreased and/or very low blood eosinophils after the steroid boost indicates that patients were able to comply with OCS treatment. Our study has some weaknesses. It included only subjects who were thought to be adherent with maintenance medications at screening, so we are unable to assess the repeatability of these measurements in a more general population with potentially higher levels of non-adherence. Given the known therapeutic benefit of OCS in some severe asthmatics ${ }^{7,8}$, long-term follow-up of subjects known to be non-adherent could be challenging from an ethical and logistical perspective (e.g. non-adherent patients may not consent to monitoring). It is possible that OCS adherence varied throughout the study, which could have introduced variability into our results beyond the reliability of the test. Our finding that some subjects were transiently classified as variably- or non-adherent, despite strong evidence of adherence at other study visits, may suggest that this was the case.

\section{Conclusions}

Our results demonstrate that assessing adherence to maintenance oral corticosteroid medication using a simple rule based on prednisolone and cortisol assays is highly reliable. Clinicians should have confidence in the results of this rule. 


\section{Declarations}

Availability of data: All data generated or analysed during this study are included in this published article and its supplementary information files.

Funding: Data were generated and supplied by Genentech Inc. Funding for the analysis was supplied by the Medical Research Council (MR/M016579/1).

Conflicts of interests: $\mathrm{CH}, \mathrm{AC}$, JGM, are employees of Genentech Inc., a Member of the Roche Group and own Roche stock. RC has attended Advisory Board Meetings for AstraZeneca, GSK, Novartis and Teva and been a speaker at meetings for AstraZeneca. She has attended conferences supported by Boehringer, Teva, AstraZeneca and received educational grants from Novartis and Aerocrine. AM received personal and department funds for talks and advisory board meetings and was sponsored to attend national and international conferences from pharmaceutical companies that include GlaxoSmithKline, Astra Zeneca, Novartis, NAPP, Boehringer Ingelheim, Roche, Chiesi. AM-G has attended advisory boards with GlaxoSmithKline, Novartis, AstraZeneca, Boehringer Ingelheim and Teva. He has received speaker fees from Novartis, AstraZeneca, Vectura, Boehringer Ingelheim, Sanofi and Teva. He has participated in research with Hoffman La Roche, GlaxoSmithKline, Boehringer Ingelheim and Astra Zeneca. He has attended international conferences with Teva and Boehringer Ingelheim and has consultancy agreements with AstraZeneca, Sanofi and Vectura. RN has received an unrestricted grant of $£ 10,000$ from Novartis in 2010 towards development of clinical services at the University Hospital of South Manchester. He has run preceptorship programmes in 2015 and 2016. These programmes have resulted in payment to the University Hospital of south Manchester for amounts not exceeding $£ 10,000$. He has also performed lecturing at Pharmaceutically sponsored meetings for the following pharmaceutical companies in the last 3 years:- Astra Zeneca $(<£ 1,000)$, Boehringer Ingelheim $(<£ 2,000)$ Boston scientific $(<£ 5,000)$ Chiesi $(<£ 1,000)$, Novartis $<£ 10,000$, Napp $(<£ 2,000)$, Teva $(<f 2,000)$. He has sat on advisory boards for the following companies in the last 3 years, (Astra Zeneca, Boehringer Ingelheim, Boston scientific, Chiesi, GSK, Novartis Vectura and Teva), receiving reimbursement not exceeding $£ 5,000$ per company. He has received sponsorship support to attend international academic meetings from Astra Zeneca, Boehringer ingelheim, 
Novartis, GSK, Chiesi and TEVA. Dr Niven, (or any members of his family) has no shares or any pecuniary interest in any pharmaceutical industry and has no shareholdings or dividends and is not a paid consultant for any company. LGH is Academic Lead for the Medical Research Council Stratified Medicine UK Consortium in Severe Asthma which involves industrial partnerships with a number of pharmaceutical companies. The remaining authors declare that they have no competing interests.

Acknowledgements: Not applicable 


\section{References}

1 Pavord ID, Beasley R, Agusti A, Anderson GP, Bel E, Brusselle G, Cullinan P, Custovic A, Ducharme FM, Fahy JV, Frey U, Gibson P, Heaney LG, Holt PG, Humbert M, Lloyd CM, Marks G, Martinez FD, Sly PD, von Mutius E, Wenzel S, Zar HJ, Bush A. After asthma: redefining airways diseases. The Lancet. 2018; 391: 350-400.

2 Gamble J, Stevenson M, McClean E, Heaney LG. The prevalence of nonadherence in difficult asthma. Am J Respir Crit Care Med. 2009; 180: 817-22.

3 Robinson DS, Campbell DA, Durham SR, Pfeffer J, Barnes PJ, Chung KF. Systematic assessment of difficult-to-treat asthma. The European respiratory journal. 2003; 22: 478-83. 4 Murphy AC, Proeschal A, Brightling CE, Wardlaw AJ, Pavord I, Bradding P, Green RH. The relationship between clinical outcomes and medication adherence in difficult-to-control asthma. Thorax. 2012; 67: 751-3.

5 Nair P, Wenzel S, Rabe KF, Bourdin A, Lugogo NL, Kuna P, Barker P, Sproule S, Ponnarambil S, Goldman M, Investigators ZT. Oral Glucocorticoid-Sparing Effect of Benralizumab in Severe Asthma. N Engl J Med. 2017; 376: 2448-58.

6 Rabe KF, Nair P, Brusselle G, Maspero JF, Castro M, Sher L, Zhu H, Hamilton JD, Swanson BN, Khan A, Chao J, Staudinger H, Pirozzi G, Antoni C, Amin N, Ruddy M, Akinlade B, Graham NMH, Stahl N, Yancopoulos GD, Teper A. Efficacy and Safety of Dupilumab in Glucocorticoid-Dependent Severe Asthma. N Engl J Med. 2018; 378: 2475-85.

7 Djukanovic R, Homeyard S, Gratziou C, Madden J, Walls A, Montefort S, Peroni D, Polosa R, Holgate $S$, Howarth $P$. The effect of treatment with oral corticosteroids on asthma symptoms and airway inflammation. American journal of respiratory and critical care medicine. 1997; 155: 826-32.

8 Sousa AR, Marshall RP, Warnock LC, Bolton S, Hastie A, Symon F, Hargadon B, Marshall H, Richardson M, Brightling CE, Haldar P, Milone R, Chalk P, Williamson R, Panettieri R, Jr., Knowles R, Bleecker ER, Wardlaw AJ. Responsiveness to oral prednisolone in severe asthma is related to the degree of eosinophilic airway inflammation. Clinical and experimental allergy : journal of the British Society for Allergy and Clinical Immunology. 2017; 47: 890-9.

9 Heaney LG, Brightling CE, Menzies-Gow A, Stevenson M, Niven RM. Refractory asthma in the UK: cross-sectional findings from a UK multicentre registry. Thorax. 2010; 65: 787-94.

10 O'Neill S, Sweeney J, Patterson CC, Menzies-Gow A, Niven R, Mansur AH, Bucknall C, Chaudhuri R, Thomson NC, Brightling CE, O'Neill C, Heaney LG. The cost of treating severe refractory asthma in the UK: an economic analysis from the British Thoracic Society Difficult Asthma Registry. Thorax. 2015; 70: 376-8.

11 National Institute for Health and Care Excellence. Omalizumab for treating severe persistent allergic asthma. NICE, London, 2013.

12 Busby J, Holweg CTJ, Chai A, Bradding P, Cai F, Chaudhuri R, Mansur AH, Lordan JL, Matthews JG, Menzies-Gow A, Niven R, Staton T, Heaney LG. Change in type-2 biomarkers and related cytokines with prednisolone in uncontrolled severe oral corticosteroid dependent asthmatics: an interventional open-label study. Thorax. 2019; 74: 806-9.

13 Payne D. Adrenal response to glucocorticoid treatment. The Lancet. 2000; 355: 1458.

14 Hagg E, Asplund K, Lithner F. Value of basal plasma cortisol assays in the assessment of pituitary-adrenal insufficiency. Clinical endocrinology. 1987; 26: 221-6. 
15 Adair CG, McCallion O, McElnay JC, Scott MG, Hamilton BA, McCann JP, Stanford CF, Nicholls DP. A pharmacokinetic and pharmacodynamic comparison of plain and entericcoated prednisolone tablets. British journal of clinical pharmacology. 1992; 33: 495-9. 16 Armbruster $\mathrm{H}$, Vetter W, Beckerhoff R, Nussberger J, Vetter $\mathrm{H}$, Siegenthaler W. Diurnal variations of plasma aldosterone in supine man: relationship to plasma renin activity and plasma cortisol. Acta endocrinologica. 1975; 80: 95-103.

17 Nakagawa S, Schielzeth H. Repeatability for Gaussian and non-Gaussian data: a practical guide for biologists. Biological reviews of the Cambridge Philosophical Society. 2010; 85: 935-56.

18 Trevethan R. Intraclass correlation coefficients: clearing the air, extending some cautions, and making some requests. Health Serv Outcomes Res Methodol. 2017; 17: 12743.

19 Koo TK, Li MY. A Guideline of Selecting and Reporting Intraclass Correlation Coefficients for Reliability Research. J Chiropr Med. 2016; 15: 155-63.

20 Gwet KL. Computing inter-rater reliability and its variance in the presence of high agreement. The British journal of mathematical and statistical psychology. 2008; 61: 29-48. 21 McHugh ML. Interrater reliability: the kappa statistic. Biochem Medica. 2012; 22: 276-82.

22 Wongpakaran N, Wongpakaran T, Wedding D, Gwet KL. A comparison of Cohen's Kappa and Gwet's AC1 when calculating inter-rater reliability coefficients: a study conducted with personality disorder samples. BMC Medical Research Methodology. 2013; 13: 61. 23 Landis JR, Koch GG. The measurement of observer agreement for categorical data. Biometrics. 1977; 33: 159-74.

24 Matsunaga KH, T. Akamatsu, K. Minakata, Y. Predictors for identifying the efficacy of systemic steroids on sustained exhaled nitric oxide elevation in severe asthma. Allergology International. 2013; 62: 359-65.

25 Sousa ARM, R. P. Warnock, L. C. Bolton, S. Hastie, A. Symon, F. Hargadon, B. Marshall, H. Richardson, M. Brightling, C. E. Haldar, P. Milone, R. Chalk, P. Williamson, R. Panettieri, R. Knowles, R. Bleecker, E. R. Wardlaw, A. J. Responsiveness to oral prednisolone in severe asthma is related to the degree of eosinophilic airway inflammation. Clin Exp Allergy. 2017; 47: 890-9.

26 Williams RL. A note on robust variance estimation for cluster-correlated data. Biometrics. 2000; 56: 645-6.

27 Lee DA, Taylor GM, Walker JG, James VH. The effect of food and tablet formulation on plasma prednisolone levels following administration of enteric-coated tablets. British journal of clinical pharmacology. 1979; 7: 523-8.

28 Hulme B, James V, Rault R. Absorption of enteric and non-enteric coated prednisolone tablets. British journal of clinical pharmacology. 1975; 2: 317-20. 


\section{Tables and Figures}

Table 1: Baseline characteristics of the study population

\begin{tabular}{|c|c|}
\hline Number of Subjects & 30 \\
\hline \multicolumn{2}{|l|}{ Demographics } \\
\hline Age (years) ${ }^{a}$ & $53.2(9.1)$ \\
\hline $21-40$ & $2(6.7 \%)$ \\
\hline $41-60$ & $22(73.3 \%)$ \\
\hline $60+$ & $5(16.7 \%)$ \\
\hline Missing & $1(3.3 \%)$ \\
\hline Female & $14(46.7 \%)$ \\
\hline Body mass index ${ }^{a}$ & $31.0(4.3)$ \\
\hline ACQ-7 score ${ }^{a}$ & $3.1(1.1)$ \\
\hline $\mathrm{AQLQ}^{\mathrm{a}}$ & $3.7(1.3)$ \\
\hline \multicolumn{2}{|l|}{ Asthma History / treatment } \\
\hline Exacerbations in prior year ${ }^{b}$ & $4.5(1.0,6.0)$ \\
\hline 0 & $2(6.7 \%)$ \\
\hline 1 & $6(20.0 \%)$ \\
\hline $2-3$ & $3(10.0 \%)$ \\
\hline $4-6$ & $12(40.0 \%)$ \\
\hline $7-10$ & $3(10.0 \%)$ \\
\hline $11+$ & 4 (13.3\%) \\
\hline Hospitalisations in prior year ${ }^{b}$ & $0.0(0.0,1.0)$ \\
\hline 0 & $18(60.0 \%)$ \\
\hline 1 & $8(26.7 \%)$ \\
\hline $2-3$ & $3(10.0 \%)$ \\
\hline $4+$ & $1(3.3 \%)$ \\
\hline Immunotherapy ever & $3(10.0 \%)$ \\
\hline Intubated ever & $4(13.3 \%)$ \\
\hline Maintenance OCS dose ${ }^{b}$ & $10.0(10.0,20.0)$ \\
\hline \multicolumn{2}{|l|}{ Lung Function } \\
\hline $\mathrm{FEV}_{1}$ (Litres) $^{\mathrm{a}}$ & $1.9(0.6)$ \\
\hline$\% \mathrm{FEV}_{1}$ Predicted ${ }^{\mathrm{a}}$ & $62(19)$ \\
\hline FVC (Litres) ${ }^{a}$ & $3.1(0.7)$ \\
\hline$\%$ FVC Predicted ${ }^{a}$ & $79(16)$ \\
\hline \multicolumn{2}{|l|}{ Type-2 Biomarkers } \\
\hline Blood Eosinophils (cells/ $\mu \mathrm{l}$ ) & $190(150,330)$ \\
\hline Periostin $(\mathrm{ng} / \mathrm{mL})^{\mathrm{b}}$ & $46(39,61)$ \\
\hline FeNO $(p p b)^{b}$ & $50(25,77)$ \\
\hline \multicolumn{2}{|l|}{ Blood Tests } \\
\hline Prednisolone $(\mathrm{nmol} / \mathrm{L})^{\mathrm{b}}$ & $454(21,678)$ \\
\hline Cortisol $(\mathrm{nmol} / \mathrm{L})^{\mathrm{b}}$ & $18(11,44)$ \\
\hline
\end{tabular}

${ }^{a}$ Mean (standard deviation)

${ }^{\mathrm{b}}$ Median (Interquartile range) 
Figure 1: Change in prednisolone levels. Patient ID appears above each individual graph and the graph data points represent the prednisolone level measured during the morning (circle) or afternoon (cross) in nmol/L. Gaps signify missing data.

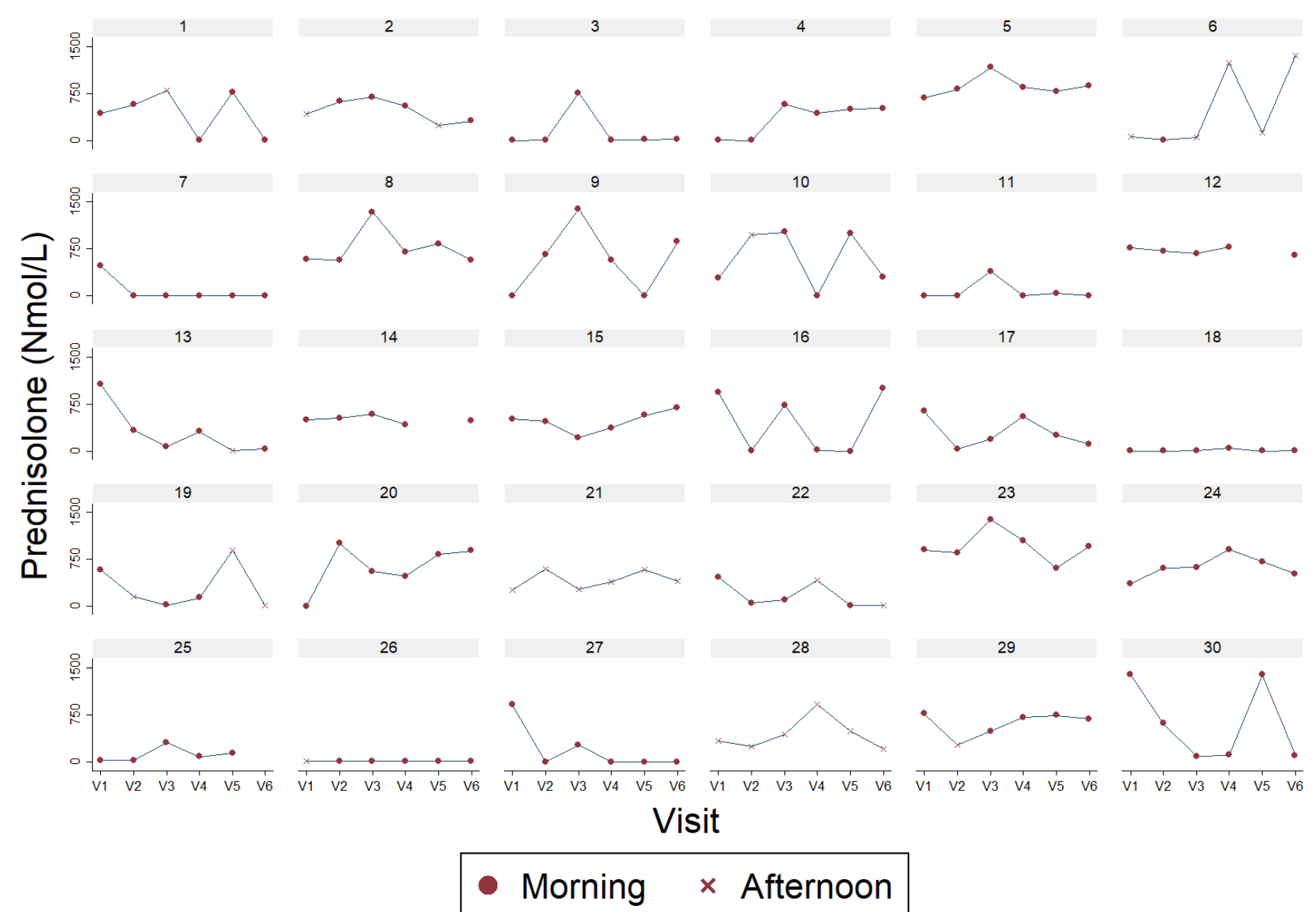


Figure 2: Change in cortisol levels. Patient ID appears above each individual graph and the graph data points represent the cortisol level measured during the morning (circle) or afternoon (cross) in nmol/L. Gaps signify missing data.

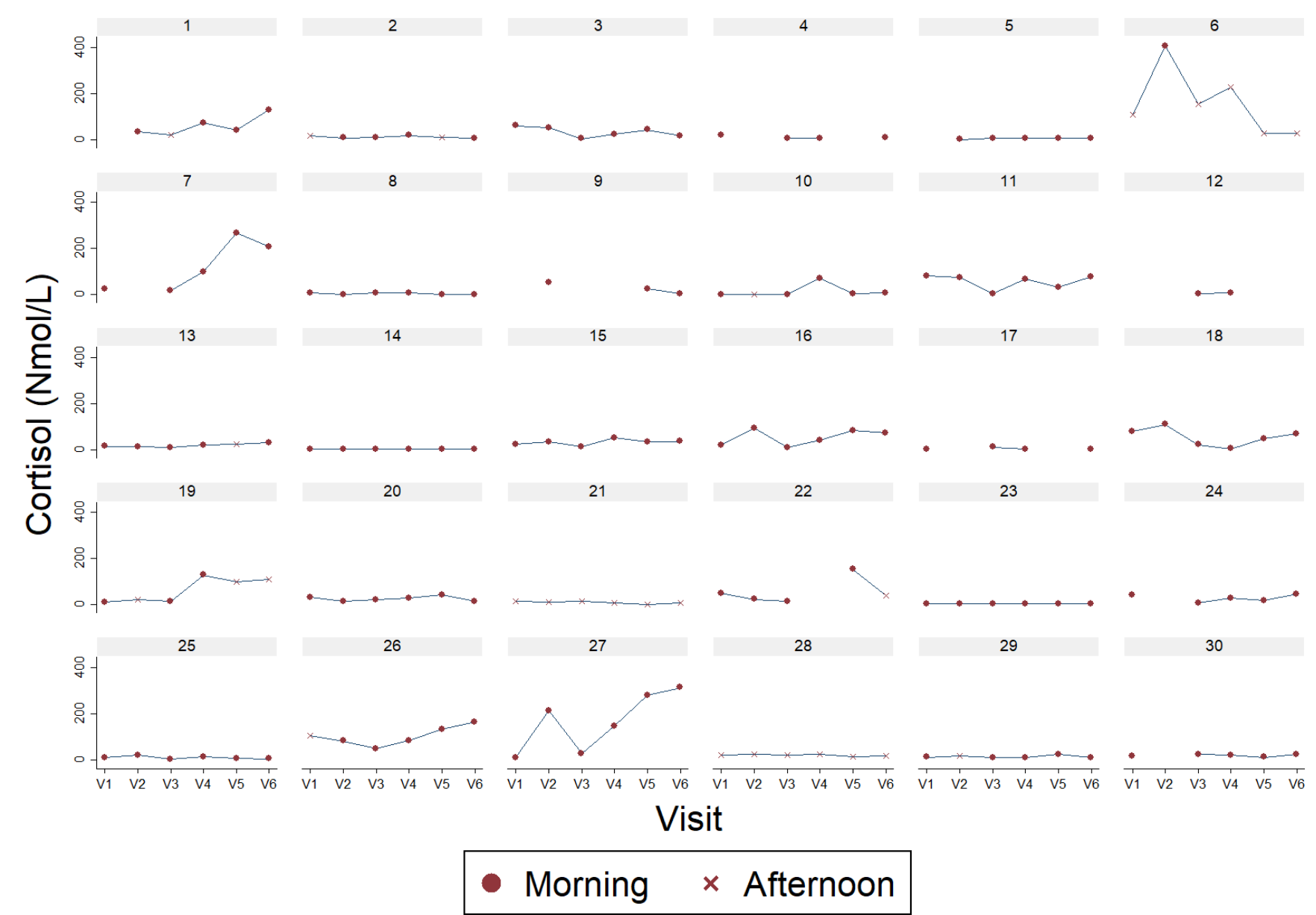


Figure 3: Change in adherence category. Patient ID appears above each individual graph and the graph data points represent the adherence cateogry measured during the morning (circle) or afternoon (cross). Patients with detectable prednisolone and abnormal cortisol ( $<100$ $\mathrm{nmol} / \mathrm{L}$ ) were categorised as adherent, those with detectable prednisolone or abnormal cortisol were categorised as variably adherent, and those with undetectable prednisolone and normal cortisol ( $\geq 100 \mathrm{nmol} / \mathrm{L}$ ) were categorsied as non-adherent. Gaps signify missing data.

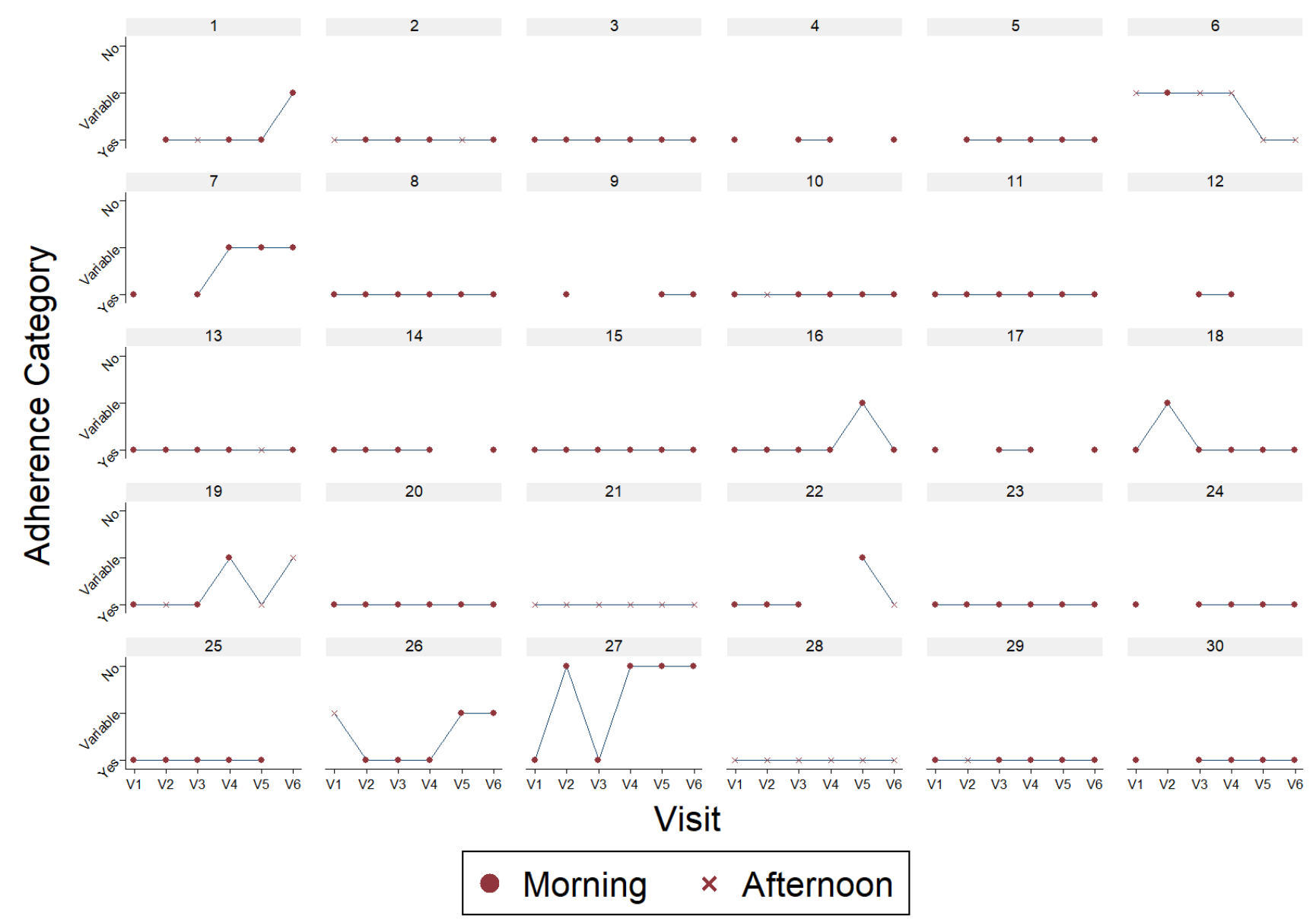




\section{Appendices}

\section{Appendix 1: Study inclusion and exclusion criteria}

\section{Inclusion Criteria}

Patients must meet the following criteria for study entry:

1. For patients considered to be minors according to national legislation in each country, the written consent of the parent or legal guardian must be obtained, as well as the assent of the minor according to his or her capacity to understand the information provided. Patients within the specified age range who are not legally considered to be minors according to national legislation must consent in their own right. Patients enrolled as minors who attain legal adulthood during the course of the study must consent in their own right at that time

2. Ability and willingness to comply with the study procedures

3. Age $\geq 12$ to $\leq 75$ years at the time of informed consent

4. Severe asthma (as defined by GINA step 5 classification of asthma severity) after a detailed systematic assessment (the BTS UK Difficult Asthma Network assessment model [Heaney et al 2010] or equivalent) and follow-up by an asthma specialist for at least six months

5. History of asthma treatment with high doses of ICS $(\geq 1500 \mu \mathrm{g}$ beclomethasone dipropionate daily, or equivalent) and LABAs, with or without an additional controller, for at least six months before Screening

6. Chronic treatment with maintenance OCS for at least six months before the time of informed consent with treatment during the last 28 days being within the following ranges:

a. $\pm 2.5 \mathrm{mg} /$ day daily dose equivalent for patients within the range of 10 to $20 \mathrm{mg} /$ day (range 5 to 20 $\mathrm{mg}$ for adolescents)

b. $\pm 5 \mathrm{mg} /$ day daily dose equivalent for patients within the range of 21 to $40 \mathrm{mg} / \mathrm{day}$

7. Baseline OCS dose as follows:

a. Adults: 10 to $40 \mathrm{mg} / \mathrm{day}$

b. Adolescents: 5 to $40 \mathrm{mg} /$ day daily dose equivalent

8. Compliance with OCS therapy will be based on prior detectable levels of serum prednisolone, cortisol suppression, or observation of Cushingoid appearance consistent with regular systemic steroid use

9. Prior assessment within the six months before the time of informed consent is obtained according to the assessment model of the BTS UK Difficult Asthma Network or equivalent to ensure a diagnosis of refractory asthma with OCS dependence on minimal effective or maximum tolerated dose, defined as follows: 
- Patient has 'uncontrolled' asthma and has detectable serum prednisolone or undetectable cortisol. 'uncontrolled' asthma is defined by any of the following:
- ACQ $-7>1.25$ or
○ Persistent blood eosinophil count $(>0.4 \times 109 / \mathrm{mL})$ or
○ Persistent sputum eosinophilia ( $>3 \%$ ) or
- Recurrent exacerbations requiring a boost in steroid dose

Note: Patients that do not meet the 'uncontrolled' asthma criteria listed previously will be defined as 'controlled'

- Patient has 'controlled' asthma and has documented evidence of previous failed OCS downtitration

Note: For patients who are controlled with no documented evidence of failed OCS down-titration, OCS dose optimisation will take place within the context of the BTS (or equivalent) standardised protocols before considering the patient for Screening (considered standard of care for optimisation daily steroid use). During this process, the OCS dose will be reduced at weekly intervals in predefined steps until either of the following criteria for OCS down-titration failure is met:

- Forced expiratory volume in 1 second (FEV1) $<80 \%$ of the patient's personal best value while on the current OCS dose, or

- Increase in 24-hour asthma symptoms, night-time awakenings, or SABA use

10. Chest x-ray or computed tomography (CT) scan obtained within the 12 months before the time of informed consent or chest $x$-ray during the screening period confirming the absence of other significant lung disease ( at the discretion of the investigator. For example a degree of co-morbid bronchiectasis is common in this population and would not exclude them. Severe forms of comorbid diseases such as emphysema and clinically significant bronchiectasis should be excluded. All cases of doubt should be discussed with the medical monitor)

11. Documented history of bronchodilator reversibility response of $\geq 12 \%$ and $\geq 200 \mathrm{~mL}$ within the past 12 months before the time of informed consent, as demonstrated by any of the following:

- Documented airflow obstruction (FEV1/forced vital capacity $[F V C]<70 \%$ ), where FEV1 has varied by $\geq 12 \%$ either spontaneously or in response to OCS therapy, or

- A decrease of $20 \%$ in FEV1 (PC20) in response to methacholine or histamine challenge at $<8$ $\mathrm{mg} / \mathrm{mL}$, indicating the presence of airway hyperresponsiveness, or

- Change in FEV1 by $\geq 12 \%$ and $\geq 200 \mathrm{~mL}$ after acute reversibility testing with $400 \mu \mathrm{g}$ salbutamol via metered dose inhaler (via spacer) or 2.5 to $5 \mathrm{mg}$ nebulised salbutamol. (This assessment 
can be undertaken during the screening period if an assessment has not been performed within the 12 months before the time of informed consent).

\section{Exclusion Criteria}

Patients who meet any of the following criteria will be excluded from study entry:

1. Baseline FEV1 $\leq 39 \%$ of predicted

2. Asthma exacerbation (as described in Section 4.2.6.5) within 28 days before the time of informed consent or during Screening

3. Major episode of infection requiring any of the following:

a. Admission to hospital for $\geq 24$ hours within the 28 days before the time of informed consent or during Screening

b. Treatment with intravenous antibiotics within the 28 days before the time of informed consent or during Screening

c. Treatment with oral antibiotics within the 14 days before the time of informed consent or during Screening

4. Active parasitic infection or Listeria monocytogenes infection within the 6 months before the time of informed consent

5. For adults: Active tuberculosis (TB) requiring treatment within the 12 months before the time of informed consent (patients are also required to have no recurrence of symptoms in the 12 months following completion of TB treatment), or For adolescents: History of active TB requiring treatment

6. Known history of severe clinically significant immunodeficiency, including, but not limited to, human immunodeficiency virus infection and/or currently receiving or have historically received intravenous Ig for treatment for immunodeficiency

Note: Immunodeficiency encompasses a wide spectrum of human conditions and/or diseases. A relative IgG deficiency that is thought, but not proven, to be a feature of severe asthma would not be exclusionary for the study. All cases of doubt should be discussed with the medical monitor 7. Evidence of acute or chronic hepatitis or known liver cirrhosis

8. Aspartate aminotransferase (AST) and/or alanine aminotransferase (ALT) and/or total bilirubin elevation $\geq 2.0$ the upper limit of normal (ULN)

9. Diagnosis or history of malignancy, or current investigation for possible malignancy

10. Other clinically significant medical disease that is uncontrolled despite treatment or that is likely, in the opinion of the investigator, to require a change in therapy or affect the ability to participate in the study 
11. History of alcohol, drug, or chemical abuse that would impair or risk the patient's full participation in the study, in the opinion of the investigator

12. Current smoker or former smoker with a smoking history of $>15$ pack-years

A current smoker is defined as someone who has smoked one or more cigarettes per day (or marijuana or pipe or cigar) for $\geq 30$ days within the 24 months before the time of informed consent and for whom cotinine testing is positive.

A former smoker is defined as someone who has smoked one or more cigarettes per day (or marijuana or pipe or cigar) for $\geq 30$ days in his or her lifetime (as long as the 30-day total did not include the 24 months before the time of informed consent) and for whom cotinine testing is negative.

A pack-year is defined as the average number of packs per day times the number of years of smoking.

13. Current use of an immunomodulatory/immunosuppressive therapy or past use within three months or five drug half-lives (whichever is longer) before the time of informed consent

14. Use of a biologic therapy (including omalizumab) at any time during the 4 months before the time of informed consent

15. History of anaphylaxis with omalizumab treatment or history of anaphylaxis to any therapeutic biological agent

16. Use of zileuton or roflumilast at any time during the two months before the time of informed consent

17. Initiation of or change in allergen immunotherapy within three months before the time of informed consent

18. Treatment with an investigational agent within 30 days of informed consent or 5 half-lives of the investigational agent, whichever is longer

19. Receipt of a live/attenuated vaccine within the 28 days before the time of informed consent, or anticipation of the receipt of live/attenuated vaccine throughout the study

20. Female patients of reproductive potential who are not willing to use a highly effective method of contraception (e.g. contraceptive pill or transdermal patch, spermicide and barrier [condoms], intrauterine device, implants for contraception, injections for contraception [with prolonged release], hormonal vaginal device, sterilisation, surgical tubal ligation, hysterectomy, or true abstinence [in adolescent patients only]) for the duration of the study

21. Female patients who are pregnant or lactating

22. Body mass index (BMI) (mass $[\mathrm{kg}] /$ height $[\mathrm{m}] 2$ ) $>38 \mathrm{~kg} / \mathrm{m} 2$

23 . Body weight $<40 \mathrm{~kg}$ 
Appendix 2: Cortisol and prednisolone measurement for individual patients

\begin{tabular}{|c|c|c|c|c|c|c|c|c|c|c|c|c|}
\hline \multirow{2}{*}{ ID } & \multicolumn{6}{|c|}{ Prednisolone (nmol/L) } & \multicolumn{6}{|c|}{ Cortisol (nmol/L) } \\
\hline & Visit 1 & Visit 2 & Visit 3 & Visit 4 & Visit 5 & Visit 6 & Visit 1 & Visit 2 & Visit 3 & Visit 4 & Visit 5 & Visit 6 \\
\hline 1 & $442(\mathrm{M})$ & $572(\mathrm{M})$ & $795(A)$ & $6(\mathrm{M})$ & $775(\mathrm{M})$ & $13(\mathrm{M})$ & & 34 (M) & $20(\mathrm{~A})$ & $72(\mathrm{M})$ & $42(\mathrm{M})$ & $130(\mathrm{M})$ \\
\hline 2 & $428(\mathrm{~A})$ & $626(M)$ & $696(M)$ & $550(\mathrm{M})$ & $241(\mathrm{~A})$ & $313(\mathrm{M})$ & $17(A)$ & $8(\mathrm{M})$ & $9(\mathrm{M})$ & $18(\mathrm{M})$ & $10(A)$ & $6(\mathrm{M})$ \\
\hline 4 & $6(\mathrm{M})$ & $4(\mathrm{M})$ & $575(\mathrm{M})$ & $441(\mathrm{M})$ & $500(\mathrm{M})$ & $519(\mathrm{M})$ & $22(\mathrm{M})$ & & $7(\mathrm{M})$ & $5(\mathrm{M})$ & & $9(\mathrm{M})$ \\
\hline 5 & $678(M)$ & $820(M)$ & $1168(\mathrm{M})$ & $850(\mathrm{M})$ & $788(\mathrm{M})$ & $875(M)$ & & $1(\mathrm{M})$ & $6(M)$ & $7(\mathrm{M})$ & $7(\mathrm{M})$ & $5(\mathrm{M})$ \\
\hline 6 & $66(A)$ & $14(\mathrm{M})$ & $44(\mathrm{~A})$ & $1238(\mathrm{~A})$ & $127(\mathrm{~A})$ & $1351(\mathrm{~A})$ & $110(\mathrm{~A})$ & 406 (M) & $153(\mathrm{~A})$ & $228(A)$ & $28(\mathrm{~A})$ & $28(A)$ \\
\hline 8 & $583(\mathrm{M})$ & $570(\mathrm{M})$ & $1337(\mathrm{M})$ & 705 (M) & 831 (M) & $576(\mathrm{M})$ & $8(\mathrm{M})$ & $1(\mathrm{M})$ & $7(\mathrm{M})$ & $8(\mathrm{M})$ & $1(\mathrm{M})$ & $1(\mathrm{M})$ \\
\hline 9 & 7 (M) & 659 (M) & $1387(\mathrm{M})$ & $568(\mathrm{M})$ & $6(\mathrm{M})$ & 864 (M) & & $54(\mathrm{M})$ & & & $25(\mathrm{M})$ & $4(\mathrm{M})$ \\
\hline 10 & $283(\mathrm{M})$ & $976(A)$ & $1019(\mathrm{M})$ & $6(\mathrm{M})$ & $1000(\mathrm{M})$ & 304 (M) & $1(\mathrm{M})$ & $1(\mathrm{~A})$ & $1(\mathrm{M})$ & 70 (M) & $6(\mathrm{M})$ & $9(\mathrm{M})$ \\
\hline 11 & $5(\mathrm{M})$ & $3(\mathrm{M})$ & 393 (M) & $4(\mathrm{M})$ & $38(\mathrm{M})$ & $3(\mathrm{M})$ & $81(\mathrm{M})$ & $76(M)$ & $5(\mathrm{M})$ & $67(\mathrm{M})$ & $33(\mathrm{M})$ & 77 (M) \\
\hline 12 & $765(\mathrm{M})$ & $718(\mathrm{M})$ & 672 (M) & $780(\mathrm{M})$ & & $652(\mathrm{M})$ & & & $4(\mathrm{M})$ & $7(\mathrm{M})$ & & \\
\hline 13 & 1066 (M) & 332 (M) & 77 (M) & 315 (M) & $10(A)$ & 40 (M) & $15(\mathrm{M})$ & $12(\mathrm{M})$ & $9(\mathrm{M})$ & $20(\mathrm{M})$ & $23(A)$ & $30(\mathrm{M})$ \\
\hline 18 & $4(\mathrm{M})$ & $3(\mathrm{M})$ & $6(\mathrm{M})$ & 49 (M) & $4(\mathrm{M})$ & $6(\mathrm{M})$ & $81(\mathrm{M})$ & 109 (M) & $22(M)$ & $4(\mathrm{M})$ & $48(\mathrm{M})$ & $68(\mathrm{M})$ \\
\hline 19 & $581(\mathrm{M})$ & $165(\mathrm{~A})$ & 24 (M) & $140(\mathrm{M})$ & $898(A)$ & $16(\mathrm{~A})$ & $11(\mathrm{M})$ & $22(\mathrm{~A})$ & $14(\mathrm{M})$ & $128(\mathrm{M})$ & $100(\mathrm{~A})$ & $110(\mathrm{~A})$ \\
\hline 20 & $2(\mathrm{M})$ & 1007 (M) & $556(\mathrm{M})$ & $478(\mathrm{M})$ & 828 (M) & 890 (M) & $32(\mathrm{M})$ & $14(\mathrm{M})$ & $21(\mathrm{M})$ & $30(\mathrm{M})$ & $44(\mathrm{M})$ & $15(\mathrm{M})$ \\
\hline 21 & $263(\mathrm{~A})$ & $602(A)$ & $273(A)$ & $399(A)$ & $592(A)$ & $408(\mathrm{~A})$ & $14(\mathrm{~A})$ & $12(\mathrm{~A})$ & $14(\mathrm{~A})$ & $10(A)$ & $1(\mathrm{~A})$ & $8(A)$ \\
\hline 22 & 465 (M) & $59(\mathrm{M})$ & $108(\mathrm{M})$ & $416(A)$ & $14(\mathrm{M})$ & $19(\mathrm{~A})$ & $50(\mathrm{M})$ & $24(\mathrm{M})$ & $14(\mathrm{M})$ & & $153(\mathrm{M})$ & $40(A)$ \\
\hline 23 & 901 (M) & 857 (M) & 1387 (M) & 1051 (M) & 609 (M) & 959 (M) & $3(\mathrm{M})$ & $3(\mathrm{M})$ & $5(\mathrm{M})$ & $4(\mathrm{M})$ & $4(\mathrm{M})$ & $4(\mathrm{M})$ \\
\hline 24 & $363(\mathrm{M})$ & 608 (M) & $622(\mathrm{M})$ & $905(\mathrm{M})$ & 711 (M) & $526(\mathrm{M})$ & $44(\mathrm{M})$ & & $7(M)$ & $30(\mathrm{M})$ & $18(\mathrm{M})$ & $47(\mathrm{M})$ \\
\hline 25 & $21(\mathrm{M})$ & $18(\mathrm{M})$ & 304 (M) & 80 (M) & 139 (M) & & $8(\mathrm{M})$ & $19(\mathrm{M})$ & $3(\mathrm{M})$ & $14(\mathrm{M})$ & 5 (M) & $4(\mathrm{M})$ \\
\hline 26 & $6(\mathrm{~A})$ & $6(\mathrm{M})$ & $11(\mathrm{M})$ & $11(\mathrm{M})$ & $8(\mathrm{M})$ & $8(\mathrm{M})$ & $104(\mathrm{~A})$ & 81 (M) & $47(M)$ & $84(\mathrm{M})$ & $132(\mathrm{M})$ & $164(\mathrm{M})$ \\
\hline 27 & 909 (M) & $1(\mathrm{M})$ & $266(\mathrm{M})$ & $1(\mathrm{M})$ & $1(\mathrm{M})$ & $1(\mathrm{M})$ & $11(\mathrm{M})$ & 212 (M) & $26(M)$ & $147(\mathrm{M})$ & $280(\mathrm{M})$ & $312(\mathrm{M})$ \\
\hline 28 & $333(\mathrm{~A})$ & $238(A)$ & $440(\mathrm{~A})$ & $912(\mathrm{~A})$ & $489(\mathrm{~A})$ & $211(\mathrm{~A})$ & $19(\mathrm{~A})$ & $22(A)$ & $19(\mathrm{~A})$ & $22(A)$ & $14(\mathrm{~A})$ & $16(\mathrm{~A})$ \\
\hline
\end{tabular}

(M): Morning; (A): Afternoon. Blank cells represent missing data. 